to the changes. Some are still concerned that they will have to take on juniors' duties and that abandoning firms will damage juniors' training and patients' continuity of care.

One of the biggest problems facing task forces has been collecting accurate data. Regions had no accurate number of senior house officer posts, and the task forces unearthed an extra 1000 such posts last year. ${ }^{5}$ Now they are concerned that they will fail to meet the next deadline of 72 hours for hard pressed posts by December 1994. So far, many signatories to the new deal have resisted the painful structural changes that are necessary. In the meantime task forces are trying to collect accurate data on actual hours worked as opposed to contracted hours.

The arguments for jettisoning the rota system are strong, but for juniors to be enthusiastic about its replacement they need a better understanding of partial shifts and their benefits and disadvantages. They should take responsibility for designing shifts and accept that shifts should be changed rather than discarded if they do not work. Managers and consultants must accept that shifts will never work unless duties are removed from junior doctors-both service work and inappropriate tasks. Juniors must be paid appropriately for the hours that they work: if they are getting only three hours' rest at night they are working the equivalent of a partial shift and should be paid accordingly.

Purchasers could give the new deal a push by insisting that providers implement it. Specifying the standard of a hospital's decor and food but ignoring the quality of its doctors' working conditions betrays a curious sense of priorities. Task forces need more power. With ministerial support they could have more financial control over juniors' posts and be responsible for verifying the information that units give to purchasers.

The new deal says that the number of hours worked, as opposed to those on duty, should be reduced to 60 as soon as practicable. To do this requires managers, consultants, and juniors to move in the same direction. That direction, however familiar and cosy it seems, is not back to rotas.

LUISA DILLNER Assistant editor

\section{$B M F$}

1 NHS Management Executive. funior doctors. The new deal. London: NHSME, 1991.

2 Department of Health and Social Security, Joint Consultants Committee, Chairmen of Health Authorities. Hospital medical staffing: achieving a balance-plan for action. London: DHSS, 1987. 3 National Confidential Enquiry into Perioperative Deaths. Report 1990. London: NCEPOD, 1992 4 Higginson I. Description and preliminary evaluation of Department of Health initiatives to reduce junior doctors' hours. London: NHS Management Executive, 1992.

5 Nichol D. funior doctors' hours. London: NHS Management Executive, 1992

\title{
Enhancing the educational content of SHO posts
}

\section{Supervisors, objectives, diaries, assessment, and feedback would all help}

In recognition of the need to separate funding for training and service, postgraduate deans will from next month have budgets to provide half the basic salary costs of all approved posts in the medical training grades in NHS provider units and trusts. ${ }^{1}$ A review of the training content of junior doctors' work is long overdue: a recent survey found that only $3 \%$ of juniors' working time was spent on training. ${ }^{2}$ The senior house officer post is a good place to start.

This is a designated training post for doctors starting out in their medical careers, during which they should acquire greater responsibility for patient care and competence in a wide range of general skills. ${ }^{3}$ Although senior house officer posts generally provide great experience, their educational potential often remains untapped. Studies have shown that guidelines on training produced by the General Medical Council $^{3}$ and the Council for Postgraduate Medical Education ${ }^{4}$ are not being followed. ${ }^{5-8}$ For example, the amount and quality of teaching vary greatly and lack any systematic approach. Consultants and senior registrars are not rewarded for teaching and seldom have been trained in educational methods. Senior house officers rarely, if ever, have a named educational supervisor or mentor with whom they can discuss problems about their training. The imbalance between service commitments and training is such that doctors have little opportunity to learn from their experiences, and little or no teaching takes place in protected time, when they would be free from service commitments. In addition, obtaining study leave is either difficult or impossible.

Some of these problems - for example, study leave-could be solved by a minor increase in resources. But the main restriction on senior house officers' training is the overwhelming dominance of service commitments over training requirements. Changing this would require a vast input of resources: the best way forward would be to capitalise on all the training opportunities thrown up by the existing system. How could this be done?
Traditionally, consultants teach juniors attached to their firm, and departments timetable teaching in the form of tutorials, case presentations, and the like. But service commitments often prevent juniors from attending these meetings, and not all senior staff enjoy or are good at teaching. New work patterns, such a partial shifts, ${ }^{9}$ mean that senior house officers are less likely to work for a single consultant and also make it more difficult for all junior doctors to attend teaching sessions at set times.

The solution would be to give all senior house officers a named educational supervisor or mentor who could coordinate an educational programme specially tailored to each senior house officer's needs. ${ }^{10}$ Suitable educational supervisors could be recruited from among consultants and senior registrars. They would need training and should receive remuneration; colleges and postgraduate deans should together be responsible for setting up such a system.

With each post should come a set of educational objectives setting out the knowledge and skills that the doctor should have acquired by the end of the post. By comparing past experience with the set objectives the doctors, together with their supervisors, could establish their own personal objectives for the post. Several colleges have produced suggested objectives, ${ }^{10}{ }^{11}$ and in some places course organisers for vocational training schemes have worked with local consultants to set up educational objectives for senior house officers who are trainee general practitioners. ${ }^{12}$

Armed with their set of personal educational objectives, doctors are in a much better position to identify what they can learn from their day to day work. ${ }^{13}$ Such learning should be reviewed, preferably by the educational supervisor; doctors should describe what they have learnt and how they intend to apply it. Later in the post it should be established how successful they have been in doing so. This learning cycle has obvious similarities to the audit cycle, which should be familiar to both senior house officers and their consultants. ${ }^{14}$ 
Using log diaries to record experience before taking membership or fellowship examinations is well established in some disciplines and could be used by senior house officers. Such a record should include the educational objectives for the post together with a system for recording whether these have been achieved and applied. Any problems could be recorded for discussion. This record should be regularly reviewed by the educational supervisor, whose responsibility would be to ensure that senior house officers had every opportunity to meet their specified objectives and that any gaps in relevant experience were readily identified and rectified. Other members of staff could also refer to the record to ensure the relevance of teaching and to avoid duplication.

After personal educational objectives have been set for each doctor the educational process should be completed by assessment of whether these objectives have been fulfilled. Senior house officers could also be assessed in terms of whether their performance in post is satisfactory. For trainee general practitioners satisfactory completion is mandatory under the terms of the NHS (vocational training) regulations. Assessment of both performance and educational achievement could benefit senior house officers provided that it occurred sufficiently early in the post to enable improvements to be made.

It would therefore be appropriate for senior house officers to have a formal assessment session with their educational supervisor part of the way through the post and again at its completion. Assessment is likely to have educational value, however, only if the outcome is fed back to the senior house officer. Arguably, assessment of performance should not be mixed with educational supervision, though manpower considerations might necessitate such a dual role for the educational supervisor. Feedback from the department to the senior house officers would close the educational loop. It would also be helpful if departments could receive feedback from the senior house officers on the quality of their education.

Pilot schemes should now be initiated in several regions and compared with traditional models. Implications for funding could then be deduced and a national policy for training senior house officers established. Given that they will have their hands on the purse strings, postgraduate deans will be able to insist on substantial improvements in the educational content of senior house officer posts. They must act on this opportunity to ensure that young doctors working in the NHS receive the training that they need and deserve.

MAUREEN BAKER

Office of the Postgraduate Dean, Clinical research fellow

University of Nottingham,

Nottingham NG7 2UH

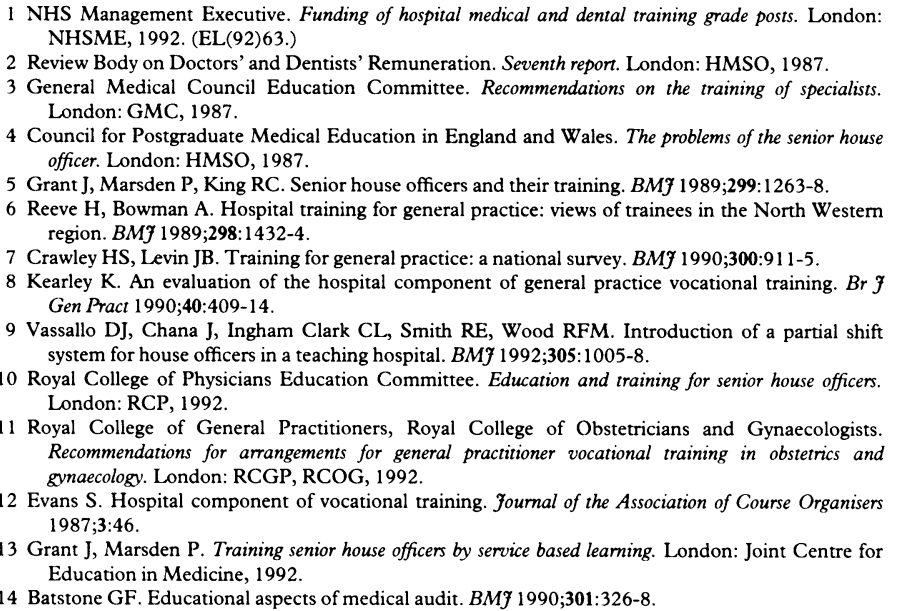

Urinary incontinence is common. In a survey reported in this week's journal MORI interviewed 4000 people aged 30 and over in their own homes on behalf of the British Association for Continence Care (p 832). ${ }^{1}$ It found that $14 \%$ of women had experienced urinary incontinence, $5.7 \%$ within the preceding week; the corresponding figures for men were about half these. Other studies have reported the difference between the sexes $^{2}$ and suggested a prevalence of urinary incontinence in adult women leading independent lives of between $22 \%$ and $45 \%$. $^{3-5}$

Whichever estimate is closest to the true prevalence, urinary incontinence is undoubtedly common in apparently healthy people, especially women. Among women, the prevalence rises with increasing age and parity and deteriorating general health. ${ }^{246}$ But even young, nulliparous, and otherwise totally healthy women experience urinary incontinence..$^{24}$

Although urinary incontinence may be no more than a nuisance in some women, for many it is far more troublesome. ${ }^{5}$ Some two thirds of women for whom incontinence occurs at least weekly regularly wear some sort of protection (such as a pad) before leaving home. ${ }^{3}$ They substantially change their lifestyles, restricting normal day to day activities such as shopping, travel, physical recreation, and choice of clothing. ${ }^{137}$ Incontinent women believe that their incontinence has affected their physical or mental health, ${ }^{7}$ and they may develop difficulties in relationships with family and friends. In a recent survey one in five incontinent women were afraid that they smelt and one in nine believed that sexual activity was compromised. ${ }^{7}$ In the MORI survey only $13 \%$ of incontinent people had ever confided their problem to their spouse.

Incontinent adults seem to have limited confidence in the medical and allied professions. Although half the incontinent people in the MORI survey had consulted their general practitioner, other surveys have suggested a much lower proportion. ${ }^{45}$ No single explanation exists for this. Clearly, some people do not consider that their problem is serious while others do not attend because of embarrassment or fear of surgery. ${ }^{13}$ One study found that nearly two thirds of patients had had their incontinence for over two years before they first sought professional advice. ${ }^{8}$ More than $90 \%$ of incontinent people, however, considered that their general practitioner would be sympathetic or helpful to their problem $^{14}$; almost half would welcome some form of treatment. ${ }^{9}$

What form should treatment take? Most incontinent women have either genuine stress incontinence or detrusor instability, or both, yet distinguishing between these two on the basis of symptoms is impossible in a quarter of patients. ${ }^{10}$ Although symptoms may give some guide to the severity of 